This is the final peer-reviewed accepted manuscript of: Roberta Dal Magro, Barbara Albertini, Silvia Beretta,Roberta Rigolio, Elisabetta Donzelli, Alessia Chiorazzi, Maurizio Ricci, Paolo Blasi and Giulio Sancini. Artificial Apolipoprotein Corona Enables Nanoparticle Brain Targeting. Nanomedicine: Nanotechnology, Biology, and Medicine 14 (2018) 429-438.

The final published version is available online at: https://www.sciencedirect.com/science/article/pii/S1549963417302034\#: :text=htt ps\%3A//doi.org/10.1016/j.nano.2017.11.008

Rights / License:

The terms and conditions for the reuse of this version of the manuscript are specified in the publishing policy. For all terms of use and more information see the publisher's website.

This item was downloaded from IRIS Università di Bologna (https://cris.unibo.it/)

When citing, please refer to the published version. 


\section{Accepted Manuscript}

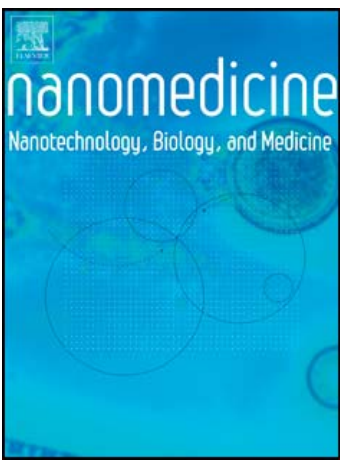

Artificial Apolipoprotein Corona Enables Nanoparticle Brain Targeting

Roberta Dal Magro PhD, Barbara Albertini PhD, Silvia Beretta MS, Roberta Rigolio $\mathrm{PhD}$, Elisabetta Donzelli $\mathrm{PhD}$, Alessia Chiorazzi PhD, Maurizio Ricci PharmD, Paolo Blasi PhD, Giulio Sancini PharmD

PII:

S1549-9634(17)30203-4

DOI: doi: 10.1016/j.nano.2017.11.008

Reference: NANO 1693

To appear in: $\quad$ Nanomedicine: Nanotechnology, Biology, and Medicine

Received date: 25 July 2017

Revised date: $\quad 25$ September 2017

Accepted date: $\quad 6$ November 2017

Please cite this article as: Magro Roberta Dal, Albertini Barbara, Beretta Silvia, Rigolio Roberta, Donzelli Elisabetta, Chiorazzi Alessia, Ricci Maurizio, Blasi Paolo, Sancini Giulio, Artificial Apolipoprotein Corona Enables Nanoparticle Brain Targeting, Nanomedicine: Nanotechnology, Biology, and Medicine (2017), doi: 10.1016/j.nano.2017.11.008

This is a PDF file of an unedited manuscript that has been accepted for publication. As a service to our customers we are providing this early version of the manuscript. The manuscript will undergo copyediting, typesetting, and review of the resulting proof before it is published in its final form. Please note that during the production process errors may be discovered which could affect the content, and all legal disclaimers that apply to the journal pertain. 


\title{
Artificial Apolipoprotein Corona Enables Nanoparticle Brain Targeting
}

Roberta Dal Magro $^{\mathrm{a}, 1}$, Barbara Albertini ${ }^{\mathrm{b}, 1}$, Silvia Beretta $^{\mathrm{c}}$, Roberta Rigolio ${ }^{\mathrm{d}}$, Elisabetta Donzelli ${ }^{\mathrm{d}}$ Alessia Chiorazzi $^{\text {d }}$, Maurizio Ricci ${ }^{\text {b }}$, Paolo Blasi ${ }^{\text {e* }}$, Giulio Sancini ${ }^{\text {a }}$

\author{
Affiliations: \\ ${ }^{\text {a }}$ School of Medicine and Surgery, Nanomedicine Center, Neuroscience Center, University of \\ Milano-Bicocca, via Cadore 48, 20900 Monza (MB), Italy \\ ${ }^{\mathrm{b}}$ Department of Pharmaceutical Sciences, University of Perugia, Via del Liceo 1, 06123 Perugia, \\ Italy. \\ ${ }^{\mathrm{c}}$ School of Medicine and Surgery, University of Milano-Bicocca, via Cadore 48, 20900 Monza, \\ MB, Italy. \\ ${ }^{\mathrm{d}}$ School of Medicine and Surgery, Neuroscience Center, University of Milano-Bicocca, via Cadore \\ 48, 20900 Monza, MB, Italy. \\ ${ }^{\mathrm{e}}$ School of Pharmacy, University of Camerino, via Gentile III da Varano, 62032 Camerino, Italy. \\ ${ }^{1}$ These authors contributed equally to this work. \\ * Corresponding Author: Paolo Blasi, email: paolo.blasi@unicam.it, phone: +390737402726.
}

Word count for abstract: 107

Word count for manuscript: 5065

Number of references: 62

Number of figures: 7

Number of tables: 0

Number of Supplementary online-only files: 0

Financial support information. This work was partially supported by the grant 2016-ATESP-0037 from the University of Milano-Bicocca. 
Abstract: Many potential therapeutic compounds for brain diseases fail to reach their molecular targets due to the impermeability of the blood-brain barrier, limiting their clinical development. Nanotechnology-based approaches might improve compounds pharmacokinetics by enhancing binding to the cerebrovascular endothelium and translocation into the brain. Adsorption of apolipoprotein E4 onto polysorbate ${ }^{\circledR} 80$-stabilized nanoparticles to produce a protein corona allows the specific targeting of cerebrovascular endothelium. This strategy increased nanoparticle translocation into brain parenchyma, and improved brain nanoparticle accumulation 3-fold compared to undecorated particles $(119.8$ vs 40.5 picomoles; $\mathrm{p}<0.01)$. Apolipoprotein-enhanced nanoparticles have high clinical translational potential and may improve the development of nanotechnology-based medicine for a variety of neurological diseases.

\section{Keywords}

Lipid nanoparticles, protein corona, apolipoprotein E4, brain targeting, blood brain barrier. 


\section{Background}

Pharmacological treatment of brain diseases is a difficult task in and of itself. Incomplete understanding of disease etiology and pathophysiology is one of the reasons for the failure of many treatments. This increases the complexity in different biomedical research fields, including drug discovery and development, by limiting the availability of safe and efficacious therapeutic compounds [1-3]. The particular anatomical and physiological features of the brain and the central nervous system in general represent a further issue. The brain is provided with different physical and metabolic barriers that tightly regulate molecular trafficking. To guarantee its complex homeostasis, the blood-brain barrier (BBB) regulates brain influx and efflux from the bloodstream of endogenous and exogenous (xenobiotic) compounds, but it is far from being a mere check point for molecular trafficking. Research in brain drug discovery and development has been hindered by a mistaken vision of the $\mathrm{BBB}$, which for decades has been considered a static lipid membrane made of endothelial cells connected by special tight junctions. Now we know that the BBB has many interactions with surrounding cells and forms part of a more complex system known as the neurovascular unit [4].

The concentration of therapeutic compounds in the brain parenchyma depends on various factors, but the ability to cross the $\mathrm{BBB}$ is of paramount importance. For small organic molecules $(<400$ Da), a correlation between brain concentration and the logarithm of the octanol/water partition coefficient has been established [5]. However, most potential central nervous system drugs and many approved compounds do not cross the $\mathrm{BBB}$ or reach the brain parenchyma in therapeutic concentrations [6]. The difficulties encountered in the treatment of brain disease with conventional pharmacological tools have created the need for alternative and innovative approaches [7].

Nanotechnology-based strategies present enormous potential in drug delivery, but this potential has yet to be sufficiently exploited. Delivery systems like liposomes [8], polymer [9] and lipid [10] nanoparticles (NPs) have been tailored to cross the BBB and to deliver their cargo in the brain. In the late eighties, it was shown that once injected into the systemic circulation, nanometer-sized 
insoluble particles coated with different surfactants exhibited different organ/tissue distribution [11 - 13]. This phenomenon was correlated with the hydrophobicity of particle surfaces $[14,15]$ and it was established that biodistribution is affected by NP surface characteristics. In fact, surface features influence the physical adsorption of circulating proteins on particle surfaces (both qualitatively and quantitatively) and the formation of the so-called protein corona, which strongly affects systemic circulation time and body distribution [16-18].

A fundamental feature of brain targeting NPs is the surface engineering to consent the adhesion to the BBB luminal side, transcytosis and brain parenchyma distribution. To this end, different strategies have been developed but, up to now, the most reliable has been the covalent functionalization of the surface with biomolecules that bind receptors overexpressed on healthy or diseased BBB [6]. There is now considerable evidence that this strategy can increase the amount of drug delivered to the brain parenchyma, but no products have reached the clinic yet [19, 20]. Among the different issues that hamper the clinical development of nanotechnology-based carriers for brain targeting, one is surely the physical and chemical complexity of NPs developed at the laboratory benches, which makes scale up difficult and creates challenges to ensuring stability for the entire shelf life of the product. Functionalization done through spacers covalently bonded to functional groups (e.g., $-\mathrm{OH},-\mathrm{COOH},-\mathrm{NH} 2$ ) of the carrier surface is complex to perform on an industrial scale, especially given difficulties related to compliance with regulatory restrictions. Moreover, NP surface functionalization with monoclonal antibodies (or part of them) or protein ligands is complicated by the need to develop side-specific binding strategies and by their marked fragility during formulation and product shelf life.

Here, we report the proof-of-concept of a NP targeting strategy with high translational potential. Lipid NPs, made of approved materials, have been functionalized by simply incubating the NP suspension with Apolipoprotein E4 (ApoE4), before intravenous administration, by taking advantage of the surfactant ability to bind the protein. This approach is supported by the finding that using particle surface modification with specific surfactants, such as polysorbate 80 , researchers 
were able to increase the concentration of the peptide dalargin delivered to the brain $[21,22]$. The mechanism of brain accumulation was credited to a preferential adsorption of certain circulating apolipoproteins [23] that bind to specific receptors on the BBB luminal side $[24,25]$. Among these proteins, ApoE has already been suggested to play a paramount role in the delivery of a number of NP-bound drugs across the BBB [26-28]. Therefore, the use of an artificial protein corona made of a single targeting protein, ApoE4, is a facile strategy for shortening the time needed to progress from the bench to the bed-side. 


\section{Methods}

\subsection{Lipid nanoparticle preparation}

Lipid NPs were prepared using the hot high pressure homogenization technique [29]. Cetyl palmitate $(0.8 \mathrm{~g})$ was melted at $65{ }^{\circ} \mathrm{C}$ and slowly added to $40 \mathrm{~mL}$ of polysorbate $80(0.2 \% \mathrm{w} / \mathrm{v})$ saline solution (conditioned at $\left.65{ }^{\circ} \mathrm{C}\right)$ under high-speed stirring $(8000 \mathrm{rpm})\left(\right.$ Ultra Turrax T25 IKA ${ }^{\circledR}$ Werke GmbH \& Co. KG, Staufen, Germany). This emulsion was then processed with a high pressure homogenizer (Avestin Emulsiflex C5, Ottawa, Canada) at the same temperature 7 times at 1500 bar. To prepare Nile red ${ }^{*}$-loaded, DiR ${ }^{\dagger}$-loaded or DiO ${ }^{\ddagger}$-loaded Lipid NPs, Nile red $(40 \mu \mathrm{M})$, $\operatorname{DiR}(50 \mu \mathrm{M})$ or DiO $(50 \mu \mathrm{M})$ were dispersed in the molten lipid in the dark and allowed to dissolve under stirring. Lipid NPs were sterilized using a polyvinylidene fluoride (PVDF) membrane (porosity $0.45 \mu \mathrm{m}$, Millipore Corporation, USA). To perform the sterilizing filtration, a glass vial provided with a rubber stopper and an aluminum seal cap was used. The PVDF membrane was placed in a stainless steel filter holder and inserted in the stopper by means of a 19 Gauge needle. A second filter $(0.45 \mu \mathrm{m}$ pore size, Corning Incorporated, USA) coupled with a needle was employed to allow air escape and avoid vial contamination during filtration. The whole system was sterilized at $121{ }^{\circ} \mathrm{C}$ for $20 \mathrm{~min}$. The hot emulsion was sampled with a $20 \mathrm{~mL}$ glass syringe (Perfectum ${ }^{\circledR}$, Popper \& Sons Inc., New Hyde Park, NY, USA) and filtered. The vial was finally cooled in an ice bath under mild agitation [30].

\subsection{Particles size and morphology determination}

Photon correlation spectroscopy (PCS) analysis was performed at $20{ }^{\circ} \mathrm{C}$ in triplicate for 15 min to determine particle size. A Nicomp 380 autocorrelator (PSS Inc., Santa Barbara, CA, USA) equipped with a Coherent Innova 70-3 (Laser Innovation, Moorpark, CA, USA) argon ion laser was used for

\footnotetext{
* 9-diethylamino-5-benzo[ $\alpha]$ phenoxazinone;

$\dagger$ 1,1'-Dioctadecyl-3,3,3',3'-tetramethylindotricarbocyanine iodide;

$\$$ 3,3'-dioctadecyloxacarbocyanine perchlorate
} 
PCS measurements. Samples were prepared by adding $2 \mu \mathrm{L}$ of the NP suspension to $3 \mathrm{~mL}$ of ultrapure water. The Nicomp 380 was also employed for the zeta potential evaluation. Samples were analyzed in triplicate at $1 \mathrm{~V} / \mathrm{cm}$ of electric field strength, using an electrode spacing of $0.4 \mathrm{~cm}$. Lipid NPs were morphologically characterized by transmission electron microscopy (TEM) (Philips EM 400T microscope, Eindhoven, Holland) and scanning electron microscopy (SEM) (Fieldemission microscope Zeiss LEO 1525 equipped with a GEMINI column, Oberkochen, Germany). Samples for TEM analysis were prepared by allowing a drop of NP suspension to dry overnight on the surface of a 200 mesh Formvar ${ }^{\circledR}$ coated copper grid (TAAB Laboratories Equipment Ltd., Aldermaston, England). Samples for SEM analysis were prepared by depositing the suspension onto a circular glass slide placed on an aluminum specimen stub covered with a double sided adhesive disc. The aqueous phase was dried overnight and then the sample was coated with a chromium layer (8 $\mathrm{nm}$ thickness) before imaging (Quorum Q150T ES East Grinstead, West Sussex, UK).

\subsection{Nanoparticle decoration}

Lipid NPs were incubated for 15 minutes at $37^{\circ} \mathrm{C}$ with increasing concentrations of recombinant human ApoE4, expressed in E. coli corresponding to 5, 10 e $20 \mu \mathrm{g}$ of protein per $\mathrm{mL}$ of $\mathrm{NP}$ suspension (or $10 \mathrm{mg}$ of lipid NPs). The Lipid NPs-ApoE4 formulations thus obtained were used for in vivo experiments. The different Lipid NP-ApoE4 suspensions were characterized in terms of particle size and zeta potential as described above and data were analyzed using t-test prism.

\subsection{The micro bicinchoninic acid assay}

The micro bicinchoninic acid (micro BCA) assay was performed to evaluate the amount of ApoE4 adsorbed on Lipid NP surfaces. The suspensions $(4 \mathrm{~mL})$ containing different concentrations of protein were centrifuged at $6000 \mathrm{~g}$ at $4^{\circ} \mathrm{C}$ for 90 minutes. Clear solution was dried under nitrogen 
flow and the solid residue dissolved in $1 \mathrm{~mL}$ of PBS and analyzed to quantify the protein amount. The absence of residual Lipid NPs in the protein solution was confirmed by PCS analysis. The assay was carried out using the BCA kit (Sigma Aldrich, Milan Italy) as described by Smith et al. [31], using albumin as a standard. The calibration curve was prepared in the concentration range of 2.5-20 $\mu \mathrm{g} / \mathrm{mL}\left(\mathrm{r}^{2}=0.9912\right)$ and validated using an ApoE4 solution $(6 \mu \mathrm{g} / \mathrm{mL})$ in PBS.

\subsection{Animals}

Male BALB/c mice, 6-8 weeks old, were purchased from Harlan Laboratories (Italy). They were housed in plastic cages, food and water were administered ad libitum and conventional conditions for laboratory animal care were respected (temperature $19-21^{\circ} \mathrm{C}$, humidity $40-70 \%, 12 \mathrm{~h}$ light/dark cycle). Mice were fed with chlorophyll-free food to avoid interference during fluorescence detection. All animal studies were conducted in accordance with the Italian laws (DL 116/92) and protocols were approved by the Institutional Animal Care and Use Committee of the University of Milano-Bicocca (ethical approval n. 0025798/12).

\subsection{In vivo treatments}

Six mice were randomly divided into three groups and administered intravenously with $100 \mu \mathrm{L}$ of Lipid NPs (33 mg/Kg of total lipids) loaded with $50 \mu \mathrm{M}$ of DiR and decorated with 5,10 or $20 \mu \mathrm{g}$ of ApoE4 per mL of suspension ( 2 mice/group). As a control, 2 mice were treated with $100 \mu \mathrm{L}$ of $50 \mu \mathrm{M}$ DiR by IV injection. The fluorescence in the brain was evaluated $30 \mathrm{~min}$ after the injection by means of Fluorescence Molecular Tomography system (FMT1500, Perkin Elmer). Mice were kept under controlled general anaesthesia (isoflurane 2.5\% - $\mathrm{O} 2$ 70\% - NO2 30\%) during the entire fluorescence detection procedure, to spare them discomfort. The total amount (in picomoles) of fluorophore in a region of interest (ROI) was calculated by the provided TrueQuant software (Perkin Elmer) using previously generated standards of the appropriate dye [32]. An operator 
unaware of the experimental origin of the specimens drew ROI in a blind manner in order to eliminate any operator bias. The performance of the most promising formulation was compared to non-decorated DiR-loaded Lipid NPs and the brain accumulation was assessed 30 min and 90 min after the IV administration (8 mice/ group, Lipid NPs vs Lipid NPs-ApoE4-treated mice).

\subsection{Brain slice preparation and immunohistochemistry}

Seven BALB/c mice were treated with $100 \mu \mathrm{L}$ of Nile red-loaded Lipid NPs-ApoE4 (5 $\mu \mathrm{g}$ of ApoE4/mL of Lipid NPs) by IV administration. Thirty minutes after the administration, mice were euthanized by cervical dislocation and brains were collected and fixed in $10 \%$ formalin solution. Brains were cut into coronal $100 \mu \mathrm{m}$ sections using a microtome (Electron Microscopy Sciences). For immunohistochemistry assay, floating sections were incubated with primary rabbit polyclonal anti- glial fibrillary acidic protein (GFAP) antibody (Dako, Milan, Italy) diluted 1:500 in 1\% NGS, 0,1\% BSA, $0,1 \%$ Triton $\mathrm{X}-100$ in PBS for 24 hours at $4^{\circ} \mathrm{C}$, under gentle agitation. Brain slices were rinsed with PBS buffer, incubated with Alexa Fluor 488 goat anti-rabbit antibodies (1:600 in NGS $1 \%$, BSA $0,1 \%$ in PBS) for 2 hours at room temperature under continuous agitation, washed in PBS and mounted on microscope slides using ProLong Gold antifade reagent (Life Technologies). confocal laser scanning microscopy (CLSM) pictures were taken using an LSM710 inverted confocal laser scanning microscope equipped with a Plan-Neofluar $63 \times / 1.4$ oil objective (Carl Zeiss, Oberkochen, Germany). Excitation was performed using Ar-laser diode (540 nm) and ultraviolet and visible $(405-488 \mathrm{~nm}) 25 \mathrm{mV}$ laser diodes. The pinhole was set to 1AU. Image acquisition was done sequentially to minimize cross-talk between the fluorophores.

\subsection{Cell culture}

Human cerebral microvascular endothelial cells (hCMEC/D3) were obtained from the Institut Cochin (INSERM, Paris, France). Cells at passages between 27 and 37 were grown on tissue culture 
flasks, covered with $0.1 \mathrm{mg} / \mathrm{ml}$ rat tail collagen type 1, in EndoGRO-MV complete medium (Merck Millipore) supplemented with $1 \mathrm{ng} / \mathrm{ml}$ basic FGF and $1 \%$ Penicillin-Streptomycin (Life Technologies). Cells were seeded at a density of $24,000-33,000$ cells $/ \mathrm{cm}^{2}$ and cultured at $37^{\circ} \mathrm{C}, 5 \%$ $\mathrm{CO}_{2}$. For flow cytometry analysis, cells were cultured on type 1 collagen-coated 12-well plates; confluent hCMEC/D3 monolayers were obtained typically by day 3 .

\subsection{Cellular uptake of Lipid NPs-ApoE4 by hCMEC/D3}

Cells were incubated with DiO-labelled Lipid NPs-ApoE4 (5 $\mu \mathrm{g}$ of ApoE4/mL of Lipid NPs), 0.1 $\mathrm{mg} / \mathrm{mL}$ of total lipids, up to $24 \mathrm{~h}$. At different time points (30 min, $90 \mathrm{~min}, 3 \mathrm{~h}$ and $24 \mathrm{~h}$ ), cells were detached using trypsin/EDTA and the cell-associated fluorescence was measured by means of FACS analysis. For inhibition experiments, hCMEC/D3 were pre-incubated with the following pharmacological inhibitors in PBS: amiloride $(100 \mu \mathrm{M})$, filipin $(3 \mu \mathrm{M})$ or chlorpromazine $(30 \mu \mathrm{M})$. After $30 \mathrm{~min}$, PBS was removed and replaced with DiO-labelled Lipid NPs-ApoE4 (5 $\mu \mathrm{g}$ of ApoE4/mL of lipid NPs), $0.1 \mathrm{mg} / \mathrm{ml}$ of total lipids, in PBS supplemented with inhibitors for $3 \mathrm{~h}$ at $37^{\circ} \mathrm{C}$. Then, cells were prepared for FACS analysis. For competition experiments, cells were incubated for 30 min at $37^{\circ} \mathrm{C}$ with DiO-labelled Lipid NPs-ApoE4 $(5 \mu \mathrm{g}$ of ApoE4/mL of Lipid NPs) and increasing amount of free ApoE4, ranging from 0.05 to $2.4 \mu \mathrm{g} / \mathrm{mL}$. Then, the cell associated fluorescence was measured by FACS analysis. Data corresponding to 20,000 events in a user-determined area were collected for every experimental condition. Samples were analyzed using DIVA software on a FACSCanto I (BD Biosciences, San Jose, California).

\subsection{Statistical analysis}

Data were expressed as mean \pm standard deviation $(\mathrm{SD})$ and analyzed by Student's $\mathrm{t}$ test. A p-value $<0.05$ was considered significant. 


\section{Results}

\subsection{Nanoparticle characterization and decoration}

Lipid NPs had a mean hydrodynamic diameter of about $180 \mathrm{~nm}$ (95.9\% of scattering intensity) and a $\zeta$-potential of $7.8 \mathrm{mV}$. A second population of smaller size ( $45 \mathrm{~nm}, 4.1 \%$ of scattering intensity) was recorded and ascribed to the presence of polysorbate 80 micelles (Fig. 1). The presence of micelles in the Lipid NP dispersion is due to a surfactant concentration higher than the critical micellar concentration, previously recorded in the range $0.0015-0.0036 \% \mathrm{w} / \mathrm{v}[33]$.

The incubation of Lipid NPs with ApoE4 increased the hydrodynamic diameter by about $25 \mathrm{~nm}$, confirming the adsorption on Lipid NP surfaces. No direct correlation between protein amount and particle size increase was observed (data not shown). In the specific case of $5 \mu \mathrm{g}$ of protein/mL, the mean hydrodynamic diameter shifted from $184 \mathrm{~nm}$ to $211 \mathrm{~nm}$ (Fig. 1) (95\% confidence interval for the differences between means from 19.64 to 34.03$)$. $\zeta$-potential was inverted from slightly positive $(7.8 \pm 1.6 \mathrm{mV})$ to slightly negative $(-10.0 \pm 0.7 \mathrm{mV})($ Fig. 1$)$.

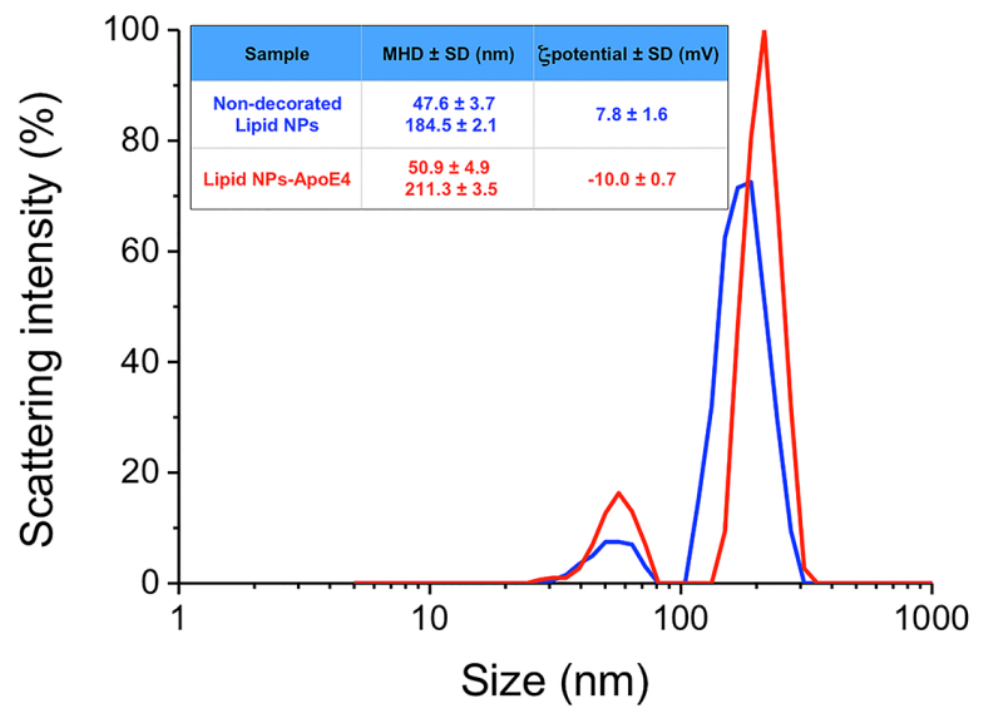

Figure 1. Particle size distribution by PCS and $\zeta$-potential data of non-decorated and ApoE4 decorated Lipid NPs (ApoE4, $5 \mu \mathrm{g} / \mathrm{mL})$. 
TEM and SEM photomicrographs confirmed the NP size estimated by PCS (Fig. 2). Particles appeared as spherical objects with a smooth surface (Fig. 2C, D) and the presence of aggregates in the TEM photomicrographs was due to particle spatial rearrangement during water vaporization for sample drying (Fig. 2A, B) [34].

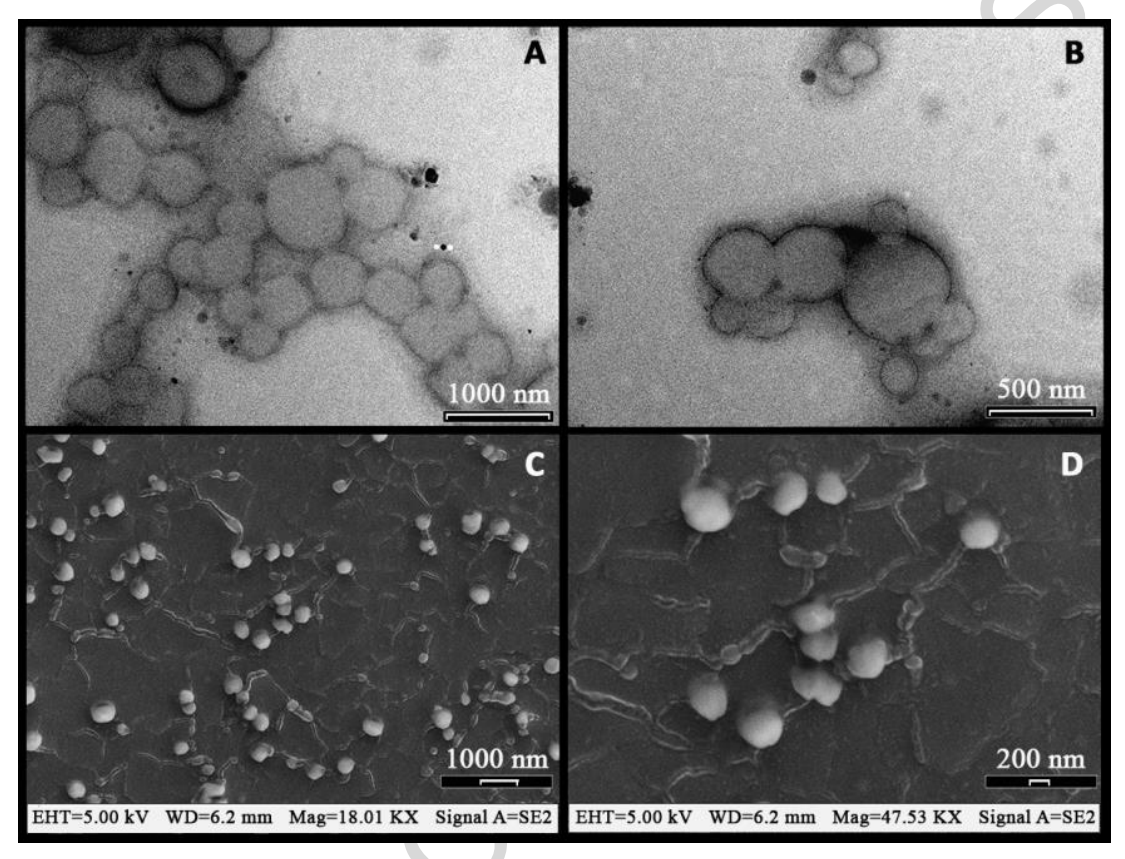

Figure 2. TEM (A and B) and SEM (C and D) photographs of Lipid NPs at different magnifications.

\subsection{Nanoparticle brain uptake in vivo}

In a pilot study, extemporaneous protein coronas were obtained by incubating Lipid NP with increasing concentrations of ApoE4 (5,10, and $20 \mu \mathrm{g}$ of protein per $\mathrm{mL}$ of NP suspension). Thirty minutes after intravenous injection, the brain-targeting ability and the accumulation in the abdomen (i.e., liver and intestine) of the different formulations were investigated by means of FMT imaging. (Fig. 3). 


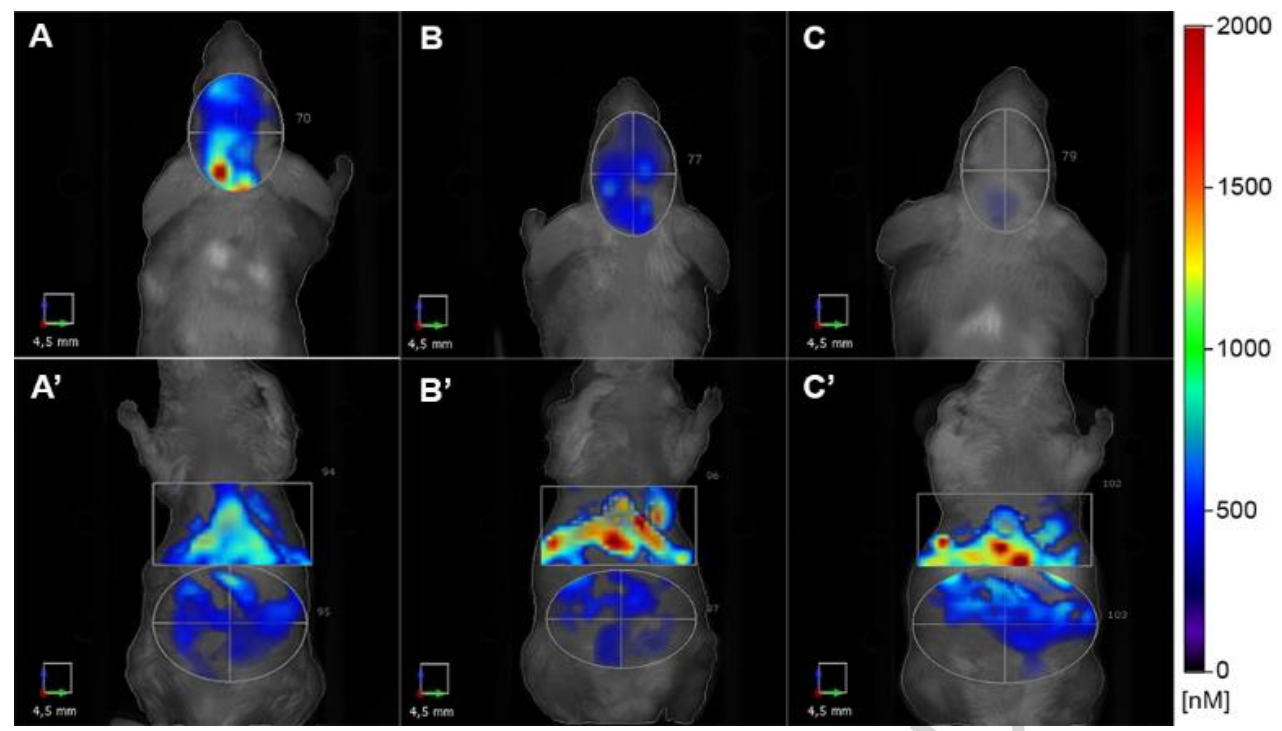

Figure 3. Representative images of fluorescence distribution to the brain $(a-c)$ and to the abdomen ( $a$ ' $\left.-c^{\prime}\right)$ 30 min after intravenous administration of Lipid NPs decorated with 5 (a, a'), 10 (b, b') and $20 \mu \mathrm{g}$ (c, c') of ApoE4 per $\mathrm{mL}$ of dispersion.

Interestingly, an inverse correlation was observed between the concentration of ApoE4 in NP suspension and the fluorescence detected in the brain. Indeed, by increasing the amount of ApoE4 up to 10 or $20 \mu \mathrm{g}$ per $\mathrm{mL}$ of dispersion, a reduction of the brain fluorescence was measured (Fig. 4A, red line). The opposite trend was observed in both the liver and the intestine: by increasing the amount of ApoE4 in the NP dispersion the amount of fluorescence detected increased. It is worth noting that the amount of protein adsorbed on NP surfaces increased slightly by increasing the ApoE4 concentration and the highest yield of adsorption was obtained by adding $5 \mu \mathrm{g}$ of protein $(4.31 \mu \mathrm{g} ; 86.2 \%)$. The percentage decreased to $51.8 \%(5.18 \mu \mathrm{g})$ and $30.5 \%(6.11 \mu \mathrm{g})$ by adding 10 and $20 \mathrm{ug} / \mathrm{mL}$ of protein, respectively. Therefore, the amount of lipid-free ApoE4 in the NP suspensions containing 10 and $20 \mu \mathrm{g} / \mathrm{mL}$ of protein was, respectively, about 7 - and 20 -fold higher than the protein amount in the formulation containing $5 \mu \mathrm{g} / \mathrm{mL}$ of ApoE4. This excess of free protein (lipid-free ApoE4) reduced brain uptake by about 4 and 26 times if compared with the best performing formulation (Fig. 4A). 


\section{A}

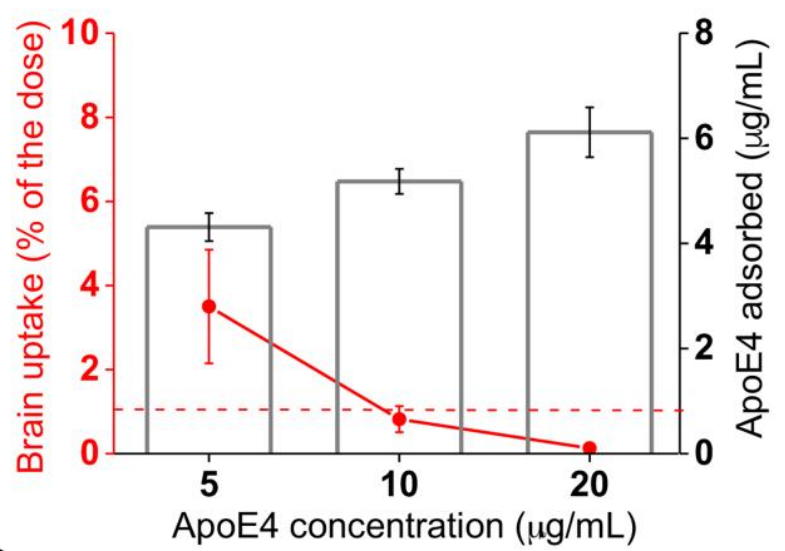

B

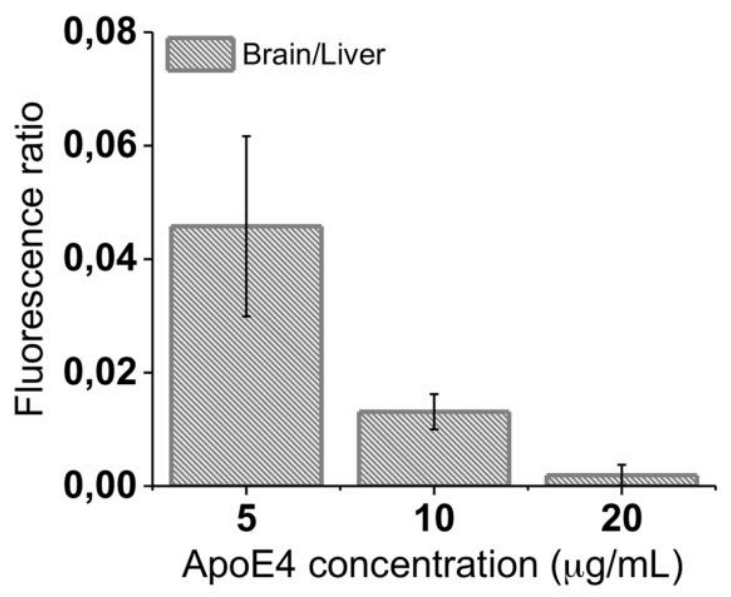

C

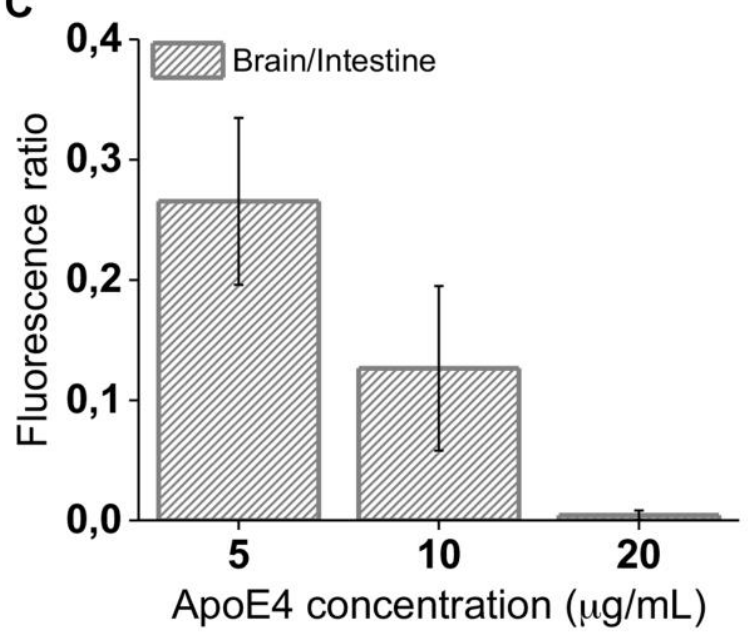

Figure 4. Quantification of Lipid NPs-ApoE4 in the brain and in the abdomen. (A) Correlation between brain uptake (red line) of Lipid NPs-ApoE4 prepared by adding 5, 10 and $20 \mu \mathrm{g} / \mathrm{mL}$ of protein and the amount of ApoE4 adsorbed on Lipid NP surface (grey columns). (B) Brain-to-liver ratio and (C) brain-tointestine fluorescence ratio obtained with Lipid NPs decorated with increasing concentration of ApoE4. 
The fluorescence accumulation in the abdomen increased by increasing the amount of ApoE4 in the suspension. Indeed, the brain-to-liver ratio decreased from about 0.045 to 0.005 by increasing the amount of ApoE4 from 5 to $20 \mu \mathrm{g} / \mathrm{mL}$ of Lipid NP suspension (Fig. 4B). The same trend was observed for the brain-to-intestine fluorescence ratio (Fig. 4C).

The ability of the artificial protein corona made of $5 \mu \mathrm{g}$ of $\mathrm{ApoE} 4 / \mathrm{mL}$ of suspension to improve Lipid NP brain targeting was assessed by measuring the amount of fluorescence detected in the brain after IV administration of decorated (5 $\mu \mathrm{g}$ of ApoE4/mL of Lipid NPs dispersion) and nondecorated formulations (Fig. 5A). Within 30 min from injection, about $1 \%$ of the dose of nondecorated Lipid NPs was able to accumulate in the brain. Fluorescence intensity was reduced by half in the following hour. In contrast, ApoE4 decorated Lipid NPs $(5 \mu \mathrm{g} / \mathrm{mL}$ of Lipid NPs) showed a 3-fold higher brain accumulation $30 \mathrm{~min}$ after injection; $90 \mathrm{~min}$ after administration, the fluorescence was still higher but not significant (Fig. 5B).

Fluorescent dye directly injected into mice systemic circulation could not be detected in the brain at the investigated time points (data not shown). 


\section{A}

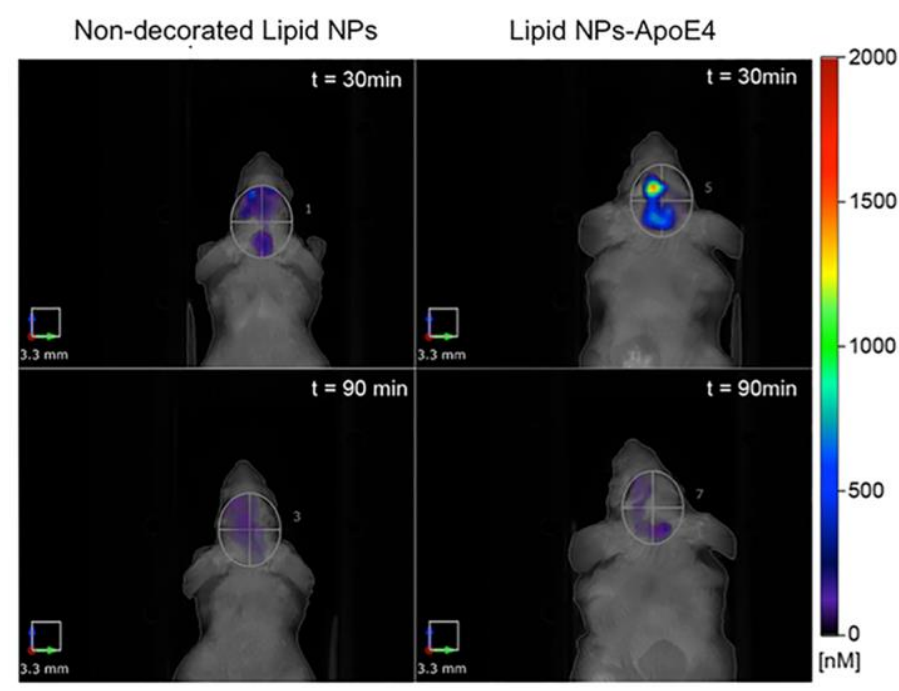

B

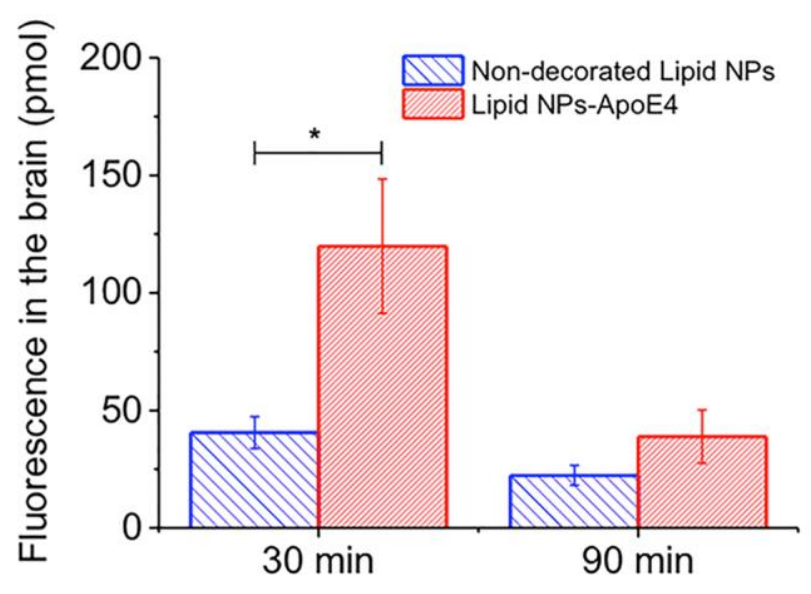

Figure 5. Comparison between fluorescence in the brain of non-decorated and ApoE4-decorated Lipid NPs. (A) Mice were treated with $100 \mu \mathrm{L}$ of non-decorated Lipid NPs or Lipid NPs-ApoE4 (ApoE4: $5 \mu \mathrm{g} / \mathrm{mL}$ ) by IV injection and each mouse was analyzed $30 \mathrm{~min}$ (upper panels) and $90 \mathrm{~min}$ (lower panels) after the administration. (B) Quantification of fluorescence ( $\mathrm{pmol}$ ) in the selected region of interest. ${ }^{*} \mathrm{p}<0.01$ by Student's $t$ test

To assess the localization of particles in the brain and to ascertain whether Lipid NPs are simply associated with the endothelium or instead are effectively translocated into the brain parenchyma, 
the distribution of decorated fluorescent NPs $(5 \mu \mathrm{g} / \mathrm{mL}$ of ApoE4) in the cerebral cortex was evaluated by CLSM. The staining of glial fibrillary acidic protein (GFAP) was performed to identify blood vessel coverage by astrocytic perivascular processes. Thirty minutes after administration, Lipid NPs-ApoE4 were clearly located both within the brain blood vessels and in the brain, confirming the ability to cross the BBB and to reach the parenchyma (Fig. 6).
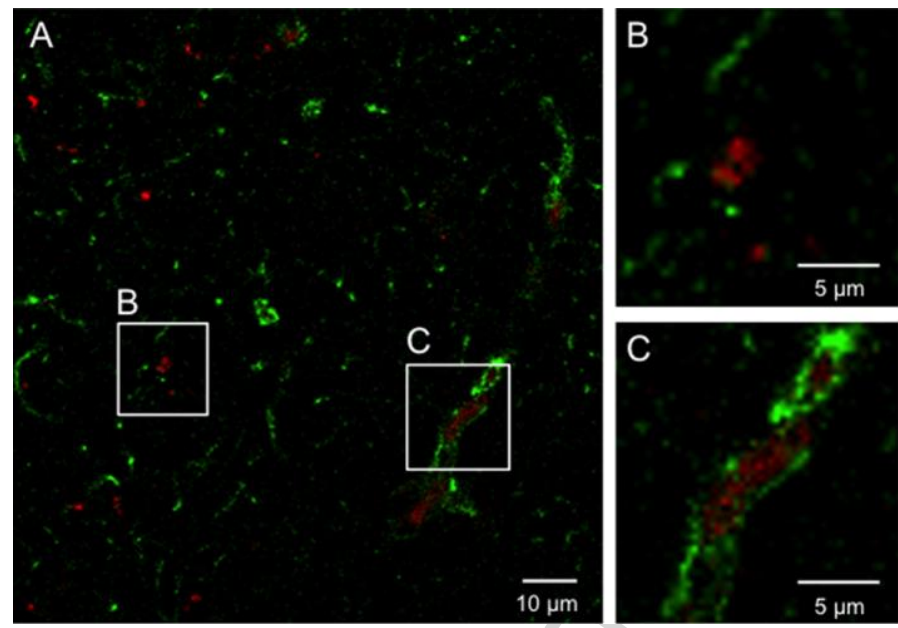

Figure 6. Lipid NPs-ApoE4 distribution in the mouse cortex. (A) 30 min after the IV administration of Nile red-loaded Lipid NPs-ApoE4, $5 \mu \mathrm{g} / \mathrm{mL}$ of ApoE4, (red spots), the fluorescence was detectable both in brain capillaries and in the brain parenchyma. Astrocyte intermediate filaments were stained using anti-GFAP antibody (green signal). (B) Magnification of Lipid NPs-ApoE4 aggregates in brain parenchyma. (C) Magnification of Lipid NPs-ApoE4 in cerebral blood capillaries.

\subsection{Nanoparticle uptake mechanisms}

To gain insights into the internalization mechanism/s responsible for $\mathrm{BBB}$ crossing and brain accumulation, fluorescent Lipid NPs decorated with $5 \mu \mathrm{g} / \mathrm{mL}$ of ApoE4 were incubated with hCMEC/D3 and the fluorescence was monitored by fluorescence-activated cell sorting (FACS) over time and after blocking specific endocytosis/macropinocytosis pathways. 
Up to $3 \mathrm{~h}$ after incubation, cell associated fluorescence increased sharply, while it remained almost stable for the following hours up to $24 \mathrm{~h}$ (Fig. 7A). The treatment of hCMEC/D3 with chlorpromazine, which inhibits the development of clathrin-coated pits, reduced the cell-associated fluorescence by $58.78 \%(\mathrm{p}<0.001)$ while the incubation with filipin produced a fluorescence reduction of $7.73 \%(\mathrm{p}<0.01)$. The incubation with amiloride did not induce statistically significant changes in the cellular uptake of ApoE4 decorated NPs, suggesting a negligible involvement of macropinocytosis in the uptake mechanisms (Fig. 7B).

To prove the involvement of a receptor-mediated internalization mechanism and the competition of ApoE4 in NP uptake, cells were incubated with fluorescent NPs decorated with $5 \mu \mathrm{g}$ of ApoE4 and different amounts of lipid-free ApoE4 (corresponding to non-adsorbed protein in suspensions added with 10 and $20 \mu \mathrm{g} / \mathrm{mL}$ of ApoE4). Results showed that the cell-associated fluorescence decreased by about $15 \%$ and $23 \%$ with the same amount of free ApoE in suspensions added with 10 and 20 $\mu \mathrm{g} / \mathrm{mL}$, while higher ApoE4 amounts did not evidenced a further significant reduction of NP uptake (Fig 7C). 

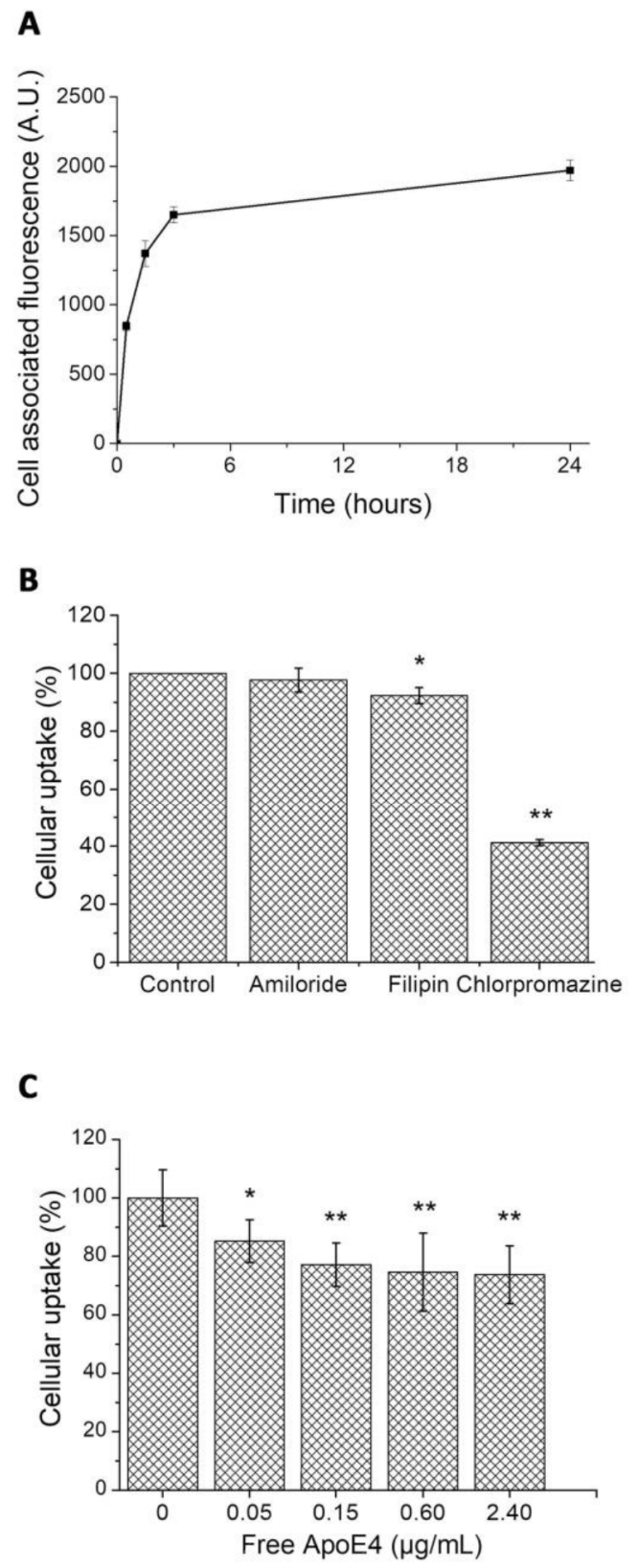

Figure 7. Uptake of Lipid NPs-ApoE4 by hCMEC/D3 cells. A) Time-dependent internalization of DiOloaded Lipid NPs-ApoE4 (5 $\mu \mathrm{g} / \mathrm{mL}$ of ApoE4) assessed by FACS analysis. B) Pathways involved in the uptake of DiO-loaded Lipid NPs-ApoE4 $(5 \mu \mathrm{g} / \mathrm{mL}$ of ApoE4) by hCMEC/D3 cells were investigated by FACS analysis after incubation of cells with amiloride, filipin or chlorpromazine for $3 \mathrm{~h} . * \mathrm{p}<0.01$, ** $\mathrm{p}<0.001$ by Student's $t$ test. C) Uptake of Lipid NPs-ApoE4 by hCMEC/D3 cells in presence of different amounts of free ApoE4 (ApoE4 non-adsorbed to Lipid NP surface).

\section{Discussion}


Brain drug development suffers from the failure of many potential therapeutic compounds to reach their molecular targets in the brain parenchyma. NPs, if appropriately decorated on their surface, are able to be taken up by brain endothelial cells and to be delivered in the brain. Even though extensive research on functionalized particles for drug targeting has been underway for the last two decades, no products for brain targeting based on this strategy have been approved [35]. Two main reasons for the clinical failure of many targeted NPs are their low stability and the cost and tedium of their multi-step preparation procedures [36].

Here, we report the proof-of-concept of an NP targeting strategy with high translational potential. Lipid NPs have been functionalized by simply incubating the NP suspension with ApoE4, before intravenous administration, by taking advantage of the surfactant ability to bind the protein. This approach may seem trivial, but we believe that its simplicity is actually the real strength of the idea. Both components can be produced and sterilized on an industrial scale and their shelf life is suitable for commercialization.

Doktorovová, reviewing the literature on lipid-based NPs, found that the $75 \%$ of the reports confirm that these carriers are safe, and noted that only negligible adverse events have been reported [37]. The toxicological profile of these NPs strongly depends on the lipids and surfactants used for the particle production. In this work, cetyl palmitate was selected as material for Lipid NP production due to its high tolerability after intravenous administration in mice compared to other lipids, such as Compritol $^{\circledR}$ [38]. Moreover, cetyl palmitate is quickly degraded by lipases and stearases, and the latter do not accumulate in the liver and spleen, thus making it possible to avoid acute or chronic pathological alterations after intravenous administration $[38,39]$. Polysorbate 80 , which has already been approved for commercial parenteral formulations such as Taxotere ${ }^{\circledR}[39,40]$ was chosen as surfactant. Lipid NPs can be easily prepared by high pressure homogenization, a technique already available on industrial scale, which allows the production of stable particles in the nanometer-size range with quality comparable to that of commercial fat emulsions for parenteral use $[29,30]$. The 
surface decoration with ApoE4 conferred to Lipid NPs a slightly negative $\zeta$-potential that might be advantageous for mimicking endogenous lipoproteins [41, 42].

The data reported here showed that 30 min after intravenous injection, the $1 \%$ of the administered dose of non-decorated Lipid NPs was able to reach the brain, probably due to the adsorption of apolipoproteins present in the blood [23]. On the contrary, the decoration of Lipid NP surface with $5 \mu \mathrm{g}$ of ApoE4 significantly increased the brain accumulation. Considering that the fluorescent dye is not able to accumulate in the brain at a detectable amount, these results are promising. By increasing the amount of ApoE4 incubated with Lipid NPs, a strong reduction of brain fluorescence was observed. This trend could be explained by the observation that the lower protein concentration has a surface saturation effect. Therefore, it seems that the increase in the amount of lipid-free ApoE4 (ApoE4 non-adsorbed to Lipid NP surface) in the NP suspension greatly compromises the brain uptake.

It is worth noting that to develop an easy translational procedure, ApoE4 decoration was made extemporaneously and the excess of protein was deliberately not removed from the suspension to avoid tedious and dangerous steps (i.e., particle aggregation) such as centrifugation and Lipid NP re-dispersion. With the described procedure, the higher the amount of protein added to Lipid NP suspension, the higher the amount of free (non-adsorbed on NP surface) protein in the administered dose. Depending on the receptor involved in Lipid NP uptake and translocation, lipid-free ApoE4 may be able to compete with ApoE4 decorated Lipid NPs at the BBB luminal side, thus decreasing the brain uptake of decorated particles.

The low-density lipoprotein (LDL) receptor family has a main role in the uptake of cholesterol and other lipids to the brain, as well as in the trafficking of the prion protein and amyloid $\beta$. In particular, LDL receptor-related protein 1 (LRP-1) is one of the main actors of these physiological and pathological pathways. LRP-1 receptor is a transmembrane receptor expressed on the BBB endothelial cells and in other brain cell types, including neurons, astrocytes and microglia [43]. This 
receptor is expressed on the luminal and abluminal side of the BBB [44] and is involved in the amyloid $\beta$ clearance, playing a critical role in the elimination of apoptotic cells containing $\mathrm{A} \beta[45$, 46]. LRP-1 is able to interact with a broad range of ligands, such as ApoE, amyloid precursor protein and lactoferrin [43]. Previous data showed that ApoE or Angiopep-2 conjugated NPs may use LRP-1 to be translocated into the brain $[47,48]$. The LRP-1 receptor binds with high affinity ApoE lipid complex but is also able to interact with ApoE4 lipid-free with weak affinity [49]. Therefore, the reduction of brain uptake produced by increasing the ApoE4 concentration in lipid NP suspensions can be explained by the ability of the LRP-1 receptor to weakly bind the lipid-free ApoE4.

To deeply investigate the interactions occurring between ApoE4 decorated Lipid NPs and the blood-brain barrier, an in vitro model of human cerebral microvascular endothelial cells was used. A major involvement of clathrin-mediated endocytosis for the uptake of Lipid NPs-ApoE4 was observed, as well as a partial competition with lipid-free ApoE4 also at low amount of the free protein (corresponding to the non-adsorbed fraction of 10 and $20 \mu \mathrm{g} / \mathrm{mL}$ of lipid dispersion). This finding supports the in vivo correlation between the amount of lipid-free ApoE4 in the Lipid NP suspension and their brain accumulation.

It is worth noting that the identification of a unique pathway in NPs uptake still remains a difficult task, due to the fact that endocytosis is a redundant process and the blockade of one pathway can lead to the up-regulation of the others [50]. The involvement of multiple endocytotic mechanisms seems to be the most reliable hypothesis also for NPs designed to exploit receptor-mediated uptake. Indeed, the interactions that occur between the NPs and the cell membrane can activate different pathways, which share a common intracellular fate [51, 52]. These results corroborate the hypothesis of the involvement of LRP-1 receptor that uses clathrin-coated pits for receptormediated uptake [53-55]. In our in vitro studies, $\sim 70 \%$ of the uptake was inhibited by blocking clathrin and caveolae-coated pits, while it is possible that the remaining $\sim 30 \%$ of fluorescent dye 
enters by different and not well understood mechanisms or simply by diffusion through the cellular membrane $[56,57]$.

One drawback to this artificial protein corona strategy could be the weakness of the interactions between the protein and the Lipid NP surface. NP-protein covalent bonds would allow greater stability. However, a protein corona is also expected to be formed over the covalently functionalized surface by masking the targeting moiety [58]. The presence of a loose layer of protein can be more efficient. In fact, protein adsorption on classical or covalently functionalized NP surfaces is an extremely fast process (nanoseconds) while the protein exchange (Vroman effect) seems to need a longer time (minutes) to reach equilibrium $[59,60]$.

Further studies are needed to characterize the stability of the artificial protein corona in physiologically relevant media (plasma and serum) and -more important- in vivo in the circulating blood of healthy and diseased animals. In fact, it will be fundamental to understand how the protein corona is affected by the shear stress of circulating blood and by the presence peculiar protein patterns in ill patients $[61,62]$.

In summary, we described a strategy to increase NP brain targeting., with a high clinical translational potential. By taking advantage of the tropism of ApoE4 for surfactant coated NPs, an extemporaneous artificial protein corona was exploited to target the cerebrovascular endothelium and to reach the brain parenchyma by NP translocation. This artificial protein corona, when tested in vivo, allowed a significant higher NP brain uptake when compared to undecorated NPs. This formulation approach may speed up the clinical development of nanotechnology-based treatments for brain disease. 
They would like to thank Sheila Beatty for editing the English usage in the manuscript. 


\section{References}

[1] Mohammad SA, Mansoor C, Qaiser MZ, Palmer AM. Drug metabolism and pharmacokinetics, the blood-brain barrier, and central nervous system drug discovery. NeuroRX 2005;2:554-571.

[2] Abbott NJ. Evidence for bulk flow of brain interstitial fluid: significance for physiology and pathology. Neurochem Int 2004;45: 545-552.

[3] Dragunow M. The adult human brain in preclinical drug development. Nat Rev Drug Discover 2008;7:659-666.

[4] Neuwelt EA, Bauer B, Fahlke C, Fricker G, Iadecola C, Janigro D, et al. Engaging neuroscience to advance translational research in brain barrier biology. Nat Rev Neurosci 2011;12:169-182.

[5] Smith QR. A review of blood-brain barrier transport techniques. Methods Mol Med 2003;89:193-208.

[6] Pardridge WM. Brain drug targeting: the future of brain drug development. Cambridge University Press, Cambridge, UK, 2001.

[7] Neuwelt EA, Abbott NJ, Abrey L, Banks WA, Blakley B, Davis T, et al. Strategies to advance translational research into brain barriers. Lancet Neurol 2008;7:84-96.

[8] Paolino D, Cosco D, Molinaro R, Celia C, Fresta M. Supramolecular devices to improve the treatment of brain diseases. Drug Discov Today 2011;16:311-324.

[9] Tosi G, Costantino L, Ruozi B, Forni F, Vandelli MA. Polymeric nanoparticles for the drug delivery to the central nervous system. Expert Opin Drug Deliv 2008;5:155-174.

[10] Blasi P, Giovagnoli S, Schoubben A, Ricci M, Rossi C. Solid lipid nanoparticles for targeted brain drug delivery. Adv Drug Deliv Rev 2007;59:454-477.

[11] Illum L, Davis SS, Müller RH, Mak E, West P. The organ distribution and circulation time of intravenous injected colloidal carriers sterically stabilized with a block copolymerpoloxamine 908. Life Sci 1987;40:367-374. 
[12] Tröster SD, Kreuter J. Contact angles of surfactants with a potential to alter the body distribution of colloidal drug carriers on poly(methyl methacrylate) surfaces. Int J Pharm 1988;45:91-100.

[13] Tröster SD, Müller U, Kreuter J. Modification of the body distribution of poly(methyl methacrylate) nanoparticles in rats by coating with surfactants. Int J Pharm 1990;61:85-100.

[14] Tröster SD, Wallis KH, Müller RH, Kreuter J. Correlation of the surface hydrophobicity of 14C poly(methyl methacrylate) nanoparticles to their body distribution. J Control Release 1992;20:247-260.

[15] Tröster SD, Kreuter J. Influence of the surface properties of the low contact angle surfactants on the body distribution of 14C poly(methyl methacrylate) nanoparticles. $J$ Microencapsul 1992;9:19-28.

[16] Monopoli MP, Walczyk D, Campbell A, Elia G, Lynch I, Baldelli Bombelli F, et al. Physical-chemical aspects of protein corona: relevance to in vitro and in vivo biological impacts of nanoparticles. J Am Chem Soc 2011;133:2525-2534.

[17] Owens DE, Peppas NA. Opsonization, biodistribution, and pharmacokinetics of polymeric nanoparticles. Int J Pharm 2006;307:93-102.

[18] Caracciolo G, Farokhzad OC, Mahmoudi M. Biological Identity of nanoparticles in vivo: Clinical implications of the protein corona. Trends Biotechnol 2017;35:257-264.

[19] Turcheniuk K, Tarasevych AV, Kukhar VP, Boukherroub R, Szunerits S. Recent advances in surface chemistry strategies for the fabrication of functional iron oxide based magnetic nanoparticles. Nanoscale 2013;5:10729-10752.

[20] Saraiva C, Praça C, Ferreira R, Santos T, Ferreira L, Bernardino L. Nanoparticle-mediated brain drug delivery: overcoming blood-brain barrier to treat neurodegenerative diseases. $J$ Control Release 2016;235:34-47. 
[21] Kreuter J, Alyautdin RN, Kharkevich DA, Ivanov AA. Passage of peptides through the blood-brain barrier with colloidal polymer particles (nanoparticles). Brain Res 1995;674:171174.

[22] Alyautdin RN, Gothier D, Petrov V, Kharkevich D, Kreuter J. Analgesic activity of the hexapeptide dalargin adsorbed on the surface of polysorbate 80-coated poly(butylcyanoacrylate) nanoparticles. Eur J Pharm Biopharm 1995;4:44-48.

[23] Göppert TM, Müller RH. Polysorbate-stabilized solid lipid nanoparticles as colloidal carriers for intravenous targeting of drugs to the brain: comparison of plasma protein adsorption patterns. J Drug Target 2005;13:179-187.

[24] Langiu M, Dadparvar M, Kreuter J, Ruonala MO. Human serum albumin-based nanoparticle-mediated in vitro gene delivery. PLoS One 2014;9:e107603- e107610.

[25] Petri B, Bootz A, Khalansky A, Hekmatara T, Müller R, Uhl R, et al. Chemotherapy of brain tumour using doxorubicin bound to surfactant-coated poly(butyl cyanoacrylate) nanoparticles: Revisiting the role of surfactants. J Control Release 2007;117:51-58.

[26] Zensi A, Begley D, Pontikis C, Legros C, Mihoreanu L, Wagner S, et al. Albumin nanoparticles targeted with Apo E enter the CNS by transcytosis and are delivered to neurones. J Control Release 2009;137:78-86.

[27] Michaelis K, Hoffmann MM, Dreis S, Herbert E, Alyautdin RN, Michaelis M, et al. Covalent linkage of apolipoprotein e to albumin nanoparticles strongly enhances drug transport into the brain. J Pharmacol Exp Ther 2006;317:1246-1253.

[28] Kreuter J, Shamenkov D, Petrov V, Ramge P, Cychutek K, Koch-Brandt C, et al. Apolipoprotein-mediated transport of nanoparticle-bound drugs across the blood-brain barrier. $J$ Drug Target 2002;10:317-325.

[29] Blasi P, Giovagnoli S, Schoubben A, Puglia C, Bonina F, Rossi C, et al. Lipid nanoparticles for brain targeting I. Formulation optimization. Int J Pharm 2011;419:287-295. 
[30] Blasi P, Schoubben A, Traina G, Manfroni G, Barberini L, Alberti PF, et al. Lipid nanoparticles for brain targeting III. Long-term stability and in vivo toxicity. Int $J$ Pharm 2013;454:316-323.

[31] Smith PK, Krohn RI, Hermanson GT, Mallia AK, Gartner FH, Frovenzano MD, et al. Measurement of protein using bicinchoninic acid. Anal Biochem 1985;19:76-85.

[32] Tsurumi C, Esser N, Firat E, Gaedicke S, Follo M, Behe M, et al. Non-invasive in vivo imaging of tumor-associated CD133/prominin. PLoS One 2010;5:e15605-e15615.

[33] Patist A, Bhagwat SS, Penfield KW, Aikens P, Shah DO. On the measurement of critical micelle concentration s of pure and technical-grade nonionic surfactants. J Surfactants Deterg 2000;3:53-58.

[34] Deegan RD, Bakajin O, Dupont TF, Huber G, Nagel SR, Witten TA. Capillary flow as the cause of ring stains from dried liquid drops. Nature 1997;389:827-829.

[35] Zhang L, Gu FX, Chan JM, Wang AZ, Langer RS, Farokhzad OC. Nanoparticles in medicine: therapeutic applications and developments. Clin Pharmacol Ther 2008;83:761-769.

[36] Valencia PM, Farokhzad OC, Karnik R, Langer R. Microfluidic technologies for accelerating the clinical translation of nanoparticles. Nat Nanotechnol 2012;7:623-629.

[37] Doktorovová S, Kovačević AB, Garcia ML, Souto EB. Preclinical safety of solid lipid nanoparticles and nanostructured lipid carriers: Current evidence from in vitro and in vivo evaluation. Eur J Pharm Biopharm 2016;108:235-252.

[38] Weyhers H, Ehlers S, Hahn H, Souto EB, Müller RH. Solid lipid nanoparticles (SLN) Effects of lipid composition on in vitro degradation and in vivo toxicity. Pharmazie 2006;61:539-544.

[39] Müller RH, Maaben S, Weyhers H, Mehnert W. Phagocytic uptake and cytotoxicity of solid lipid nanoparticles (SLN) sterically stabilized with poloxamine 908 and poloxamer 407. J Drug Target 1996;4:161-170. 
[40] Engels FK, Mathot RA, Verweij J. Alternative drug formulations of docetaxel: a review. Anticancer Drugs 2007;18:95-103.

[41] Pande AH, Tripathy RK, Nankar SA. Membrane surface charge modulates lipoprotein complex forming capability of peptides derived from the C-terminal domain of apolipoprotein E. Biochim Biophys Acta 2009;1788:1366-1376.

[42] Sparks DL, Chatterjee C, Young E, Renwick J, Pandey NR. Lipoprotein charge and vascular lipid metabolism. Chem Phys Lipids 2008;154:1-6.

[43] Rebeck GW, Reiter JS, Strickland DK, Hyman BT. Apolipoprotein E in sporadic Alzheimer's disease: allelic variation and receptor interactions. Neuron 1993;11:575-580.

[44] Zlokovic BV, Deane R, Sagare AP, Bell RD, Winkler EA. Low-density lipoprotein receptorrelated protein-1: a serial clearance homeostatic mechanism controlling Alzheimer's amyloid $\beta$ peptide elimination from the brain. J Neurochem 2010;115:1077-1089.

[45] Kanekiyo T, Liu CC, Shinohara M, Li J, Bu G. LRP1 in brain vascular smooth muscle cells mediates local clearance of Alzheimer's amyloid- $\beta$. J Neurosci 2012;32:16458-16465.

[46] Kanekiyo T, Bu G. The low-density lipoprotein receptor-related protein 1 and amyloid- $\beta$ clearance in Alzheimer's disease. Front Aging Neurosci 2014;6:93-105.

[47] Wagner S, Zensi A, Wien SL, Tschickardt SE, Maier W, Vogel T, et al. Uptake mechanism of ApoE-modified nanoparticles on brain capillary endothelial cells as a blood-brain barrier model. Plos One 2012;7:e32568-e32575.

[48] Tian X, Nyberg S, Sharp PS, Madsen J, Daneshpour N, Armes SP, et al. LRP-1-mediated intracellular antibody delivery to the central nervous system. Scientific Reports 2015;5:1199012004.

[49] Ruiz J, Kouiavskaia D, Migliorini M, Robinson S, Saenko EL, Gorlatova N, et al. The apoE isoform binding properties of the VLDL receptor reveal marked differences from LRP and the LDL receptor. J Lipid Res 2005;46:1721-1731. 
[50] Doherty GJ, McMahon HT. Mechanisms of endocytosis. Annu Rev Biochem 2009;78:857902.

[51] Eltoukhy AA, Sahay G, Cunningham JM, Anderson DG. Niemann-Pick C1 affects the gene delivery efficacy of degradable polymeric nanoparticles. ACS Nano 2014;8:7905-7913.

[52] Duncan R, Gaspar R. Nanomedicine(s) under the microscope. Mol Pharm 2012;9:23802402.

[53] Taylor DR, Hoope NM. The low-density lipoprotein receptor-related protein 1 (LRP1) mediates the endocytosis of the cellular prion protein. Biochem $J$ 2007;402:17-23.

[54] Willnow TE. The low-density lipoprotein receptor gene family: multiple roles in lipid metabolism. J Mol Med 1999;77:306-315.

[55] Takayama Y, May P, Anderson RGW, Herz J. Low density lipoprotein receptor-related protein 1 (LRP1) controls endocytosis and c-CBL-mediated ubiquitination of the plateletderived growth factor receptor $\beta$ (PDGFR $\beta$ ). J Biol Chem 2005;280:18504-18510.

[56] Kleusch C, Hersch N, Hoffmann B, Merkel R, Csiszár A. Fluorescent lipids: functional parts of fusogenic liposomes and tools for cell membrane labeling and visualization. Molecules 2012;17:1055-1073.

[57] Pietzonka P, Rothen-Rutishauser B, Langguth P, Wunderli-Allenspach H, Walter E, Merkle HP. Transfer of lipophilic markers from PLGA and polystyrene nanoparticles to caco-2 monolayers mimics particle uptake. Pharm Res 2002;19:595-601.

[58] Salvati A, Pitek AS, Monopoli MP, Prapainop K, Bombelli FB, Hristov DR, et al. Transferrin-functionalized nanoparticles lose their targeting capabilities when a biomolecule corona adsorbs on the surface. Nat Nanotechnol 2013;8:137-143.

[59] Vilaseca P, Dawson KA, Franzese G. Understanding and modulating the competitive surface-adsorption of proteins through coarse-grained molecular dynamics simulations. Soft Matter 2013;9:6978-6985. 
[60] Vroman L, Adams AL, Fischer GC, Munoz PC. Interaction of high molecular weight kininogen, factor xii, and fibrinogen in plasma at interfaces. Blood 1980;55:156-159.

[61] Colapicchioni V, Tilio M, Digiacomo L, Gambini V, Palchetti S, Marchini C, et al. Personalized liposome-protein corona in the blood of breast, gastric and pancreatic cancer patients. Int J Biochem Cell Biol 2016;75:180-187.

[62] Corbo C, Molinari R, Tabatabaei M, Farokhzad OC, Mahmoudi M. Personalized protein corona on nanoparticles and its clinical implications. Biomater Sci 2017;5:378-387. 
Extemporaneous Apolipoprotein E4 decoration allows lipid nanoparticles to cross the blood-brain barrier and to reach the brain parenchyma 


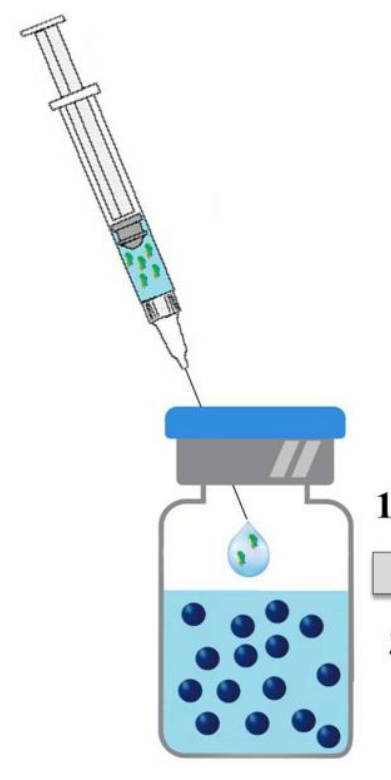

答 Apo-E4

Graphical Abstract

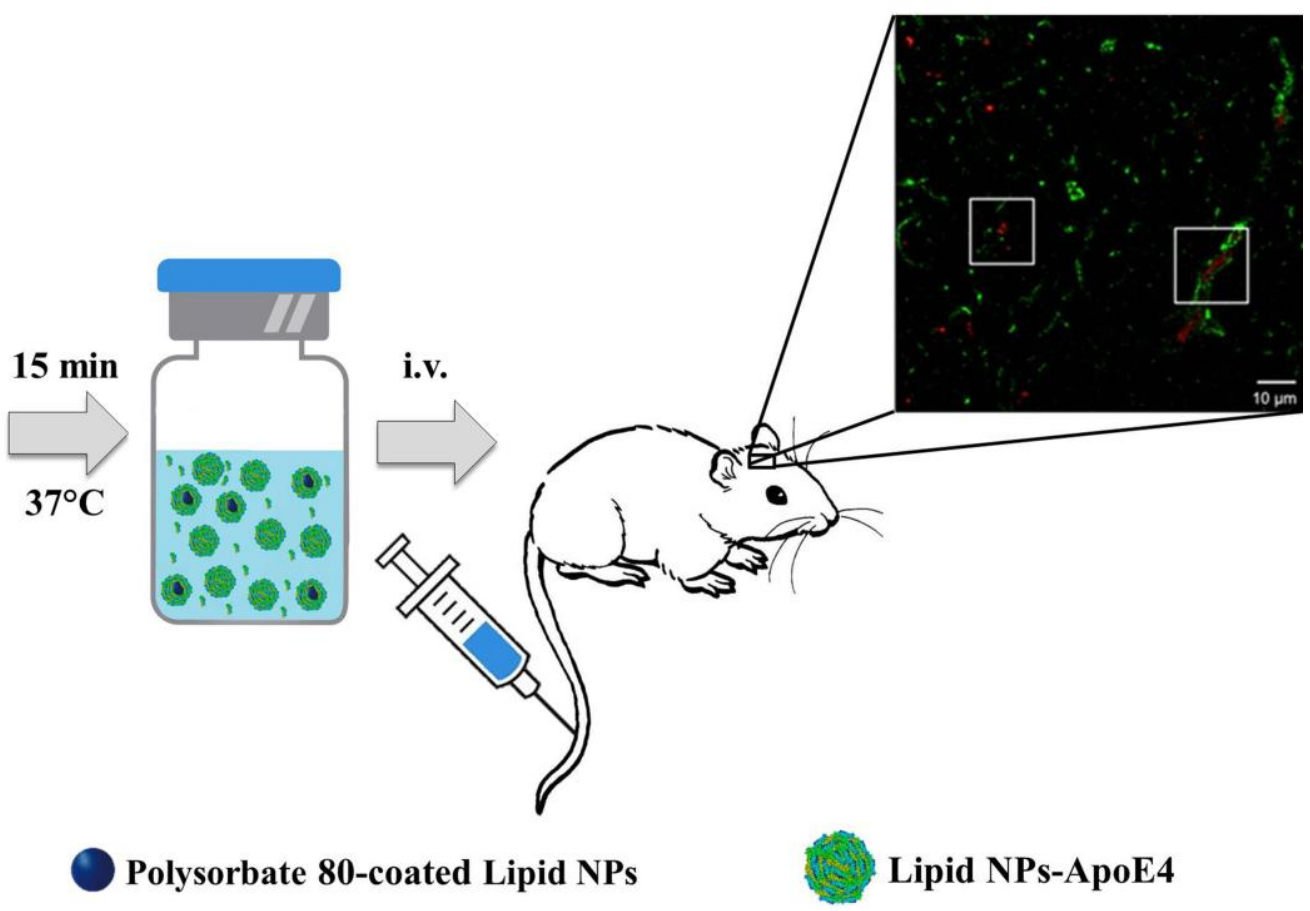

